\title{
Araneofauna capturada no interior da mata e área de pastagem adjacente, no norte do Paraná, Brasil
}

\section{Araneofauna captured inside the forest and adjacent pasture area in northern Paraná, Brazil}

\author{
José Lopes ${ }^{1} ;$ Fernando Pereira dos Santos² ${ }^{2}$ Isis Meri Medri ${ }^{3}$
}

\section{Resumo}

Os aracnídeos compõem um grupo exclusivamente predador. O hábito alimentar faz com que o artrópoda locomova-se em busca da caça ou construa armadilhas com seus com fios de seda. Buscando conhecer a araneofauna do Parque Estadual Mata dos Godoy, foram instaladas armadilhas tipo ptiffal no interior da mata e em área de pastagem adjacente, com predominância de gramíneas. As coletas foram realizadas quinzenalmente, no período de quatro meses. Foram coletados 346 indivíduos, pertencentes a 19 famílias, onde as famílias mais numerosas foram Lycosidae e Lyniphiidae nas áreas de pastagem e interior da mata, respectivamente.

Palavras-chave: Aranaeofauna. Diversidade. Ptifall.

\begin{abstract}
The arachnids make up an exclusive predatory group. The eating habit makes the arthropoda to move in search of food or to build snares with its silk threads. In order to know the araneofauna of the State Park "Godoy's Forest", pitfall snares were set inside the forest and in the adjacent grass-predominant pasture area. Collections were done every fifteen days in a four-month period. Three hundred and forty-six individuals were collected, belonging to 19 families, the most numerous ones being the Lycosidae and the Lyniphiidae in the pasture areas as well as inside the forest, respectively.
\end{abstract}

Key words: Araneofauna. Diversity. Pitfall.

Departamento de Biologia Animal e Vegetal, Universidade Estadual de Londrina. Londrina, Paraná, Brasil. E-mail: jea@ uel.br. Aluno do programa de Mestrado em Agronomia, Universidade Estadual de Londrina, Campus Universitário, Londrina, Paraná, Brasil.E-mail: nando@uel.br.

3 Aluna do programa de pós graduação em Ecologia, Instituto de Ciências Biológicas, Universidade de Brasília, Brasília. E-mail: isismedri@gmail.com. 


\section{Introdução}

A ordem Araneae é o segundo maior grupo dentre os aracnídeos Foelix (apud BENATI, 2005).Este grupo, apesar de pouco estudado (CODDINGTON; LEVI, 1991), é considerado de grande importância ecológica (SIMÓ et al., 1994). Compreende uma porção bastante significativa da diversidade de artrópodes terrestres (TOTI; COYLE; MILLER, 2000), e constitui um dos grupos mais diversos e abundantes com 38.663 espécies incluídas em 110 famílias (PLATNICK, 2004).

A maioria das espécies são sensíveis a diversos fatores físicos, (como temperatura, umidade, vento e intensidade luminosa) e fatores biológicos, (como estrutura da vegetação e disponibilidade de alimento) (FOELIX, 1996). As aranhas apresentam mais exigências do que outros grupos que vivem no mesmo habitat (METZGER, 2003), e podem ser utilizadas como bioindicadores para diagnósticos de uma determinada área (OLIVEIRA-ALVES, 2005).

No Brasil, as regiões fitogeográficas mais estudadas são a Floresta Amazônica (HOFER, 1998; BORGES; BRESCOVIT, 1996) Martins e Lise (apud INDICATTI, 2005) e a Mata Atlântica (BRESCOVIT; BONALDO; RHEIMS, 2004). Estima-se que sejam conhecidas apenas $30 \%$ das aranhas brasileiras.

O objetivo deste estudo foi conhecer a diversidade de aranhas de solo em dois ambientes distintos: interior da mata e área de pastagem adjacente no Norte do Paraná, Brasil, por meio de análise do material biológico capturado em armadilha de solo.

\section{Material e Métodos}

Parte do estudo foi realizado no Parque Estadual Mata dos Godoy, sob o Trópico de Capricórnio, localizado no Estado do Paraná, município de Londrina, à aproximadamente $15 \mathrm{~km}$ do centro da cidade $\left(23^{\circ} 27^{\prime} \mathrm{S}\right.$ e $\left.51^{\circ} 15^{\prime} \mathrm{W}\right)$, com altitude em torno de 600 metros.

O parque apresenta 680 hectares, dos quais 580 ha são constituídos de floresta contínua em boas condições de preservação e os 100 ha restantes constituem áreas de reflorestamento e de floresta secundária, área aberta com predominância de Panicum maximum (capim colonião). Para comparação foram também montadas armadilhas em área de pastagem adjacente que dista aproximadamente 900 metros do limite sul do parque, a qual se diferencia das pastagens tradicionais por apresentar muitas ervas e arbustos, além de algumas árvores distribuídas aleatoriamente pela área. Nessa área é notável a visualização do início do processo de sucessão secundária.

As coletas foram realizadas no interior da mata e em área aberta de pastagem adjacente com periodicidade quinzenal, entre 11 de dezembro de 1998 e 27 de abril de 1999, e as armadilhas permaneceram instaladas durante 15 dias. Para as coletas utilizou-se armadilha de solo (pitffal), constituída de recipientes plásticos de $23 \mathrm{~cm}$ de comprimento e $9,5 \mathrm{~cm}$ de diâmetro. A 2,0 cm da borda destes, existia um pequeno frasco $(3,0 \mathrm{~cm} \mathrm{X} 5,0 \mathrm{~cm})$ utilizado como porta-iscas (50 gramas de carne bovina), pois tratava-se de um amplo experimento para estudo de entomofauna de solo._Em cada armadilha, foram acrescidas $200 \mathrm{~mL}$ de formalina a $4 \%$. Para evitar a excessiva queda de terra no interior dos recipientes, foi acoplado em torno da abertura de cada armadilha, um suporte de madeira. Foram alocadas quatro armadilhas por ambiente; M1, M2, M3 e M4, para a área de mata e P1, P2, P3 e P4 para a área de pastagem, sendo que as armadilhas M1 e P1 não continham isca.

O material coletado foi acondicionado em potes plásticos com capacidade de $500 \mathrm{~mL}$, acrescidos com álcool $70 \%$. No laboratório, as aranhas foram triadas posteriormente, enviadas para identificação por especialista da área.

Para verificar a variação populacional foram elaborados gráficos de barras, utilizando as famílias mais abundantes. Com a finalidade de estudar a diversidade, foi utilizado o índice de Shannon (MAGURRAN, 1988).

As amostras das aranhas capturadas estão depositadas no Laboratório de Entomologia Médica da Universidade Estadual de Londrina. 


\section{Resultados e Discussão}

Foram coletadas 343 aranhas, sendo que 219 $(63,85 \%)$ encontradas na área pastagem e 124 $(36,15 \%)$ no interior da mata. A forma jovem foi predominante com $208(60,1 \%)$ indivíduos, em relação à forma adulta presente em 138 (39,9\%) exemplares. Este resultado é semelhante ao encontrado por Rodrigues (2005), segundo o qual mais de $70 \%$ do material coletado foi representado por forma jovem. A queda na armadilha desta forma imatura pode estar relacionada a sua dispersão, que ocorre com mais intensidade nessa fase da vida. A dispersão ativa que ocorre logo nos primeiros dias de vida, leva-os a colonizar diferentes espaços evitando principalmente o canibalismo entre eles.

Estes aracnídeos foram identificados como pertencentes a 19 famílias e 20 gêneros, dentre estas, as mais abundantes foram Lycosidae $(45,66 \%)$, Linyphiidae $(18,21 \%)$ e Theridiidae $(11,85 \%)$ (Tabela 1). Rodrigues (2005), estudando a araneofauna de solo numa mata de restinga no município de Capão do Leão, Rio Grande do Sul, também encontrou aranhas família Lycosidae como uma das mais abundantes. É uma família comum na região neotropical, predominando em ambientes abertoscom gramíneas. Ott (apud RODRIGUES, 2005) em trabalhos realizados em mata de restinga no Rio Grande do Sul, verificou que as famílias mais numerosas foram Linyphiidae, Theridiidae, Amaurobiidae e Oonopidae. Enquanto que Flórez (1999), estudando uma comunidade de aranhas em um bosque na Colômbia, observou a predominância de Lycosidae, Amaurobiidae, Theridiidae e Salticidae.

A predominância de Lycosidae na área de pastagem (Tabela 1) é um indicativo de que estes organismos apresentam uma plasticidade genética que permite colonizar ambientes abertos com maior influência humana, e mostra que eles podem ser estudados visando à sua utilização como indicadores biológicos.

A família Linyphiidae apresentou uma diferença na distribuição nos dois ecótopos, sendo 27 indivíduos $(69,23 \%)$ coletados no interior da mata e 12 indivíduos na área de pastagem $(30,77 \%)$. Esta família foi a mais abundante em um trabalho realizado por Indicatti et al. (2005) representando mais de 60\% das espécimes coletadas na área de estudo. As aranhas desta família são típicas de serrapilheira, existindo também espécies que ocupam estratos superiores de vegetação, condição encontrada na área estudada.

A família Theridiidae foi a terceira mais abundante, resultado semelhante encontrado por Candiani, Indicatti e Brescovit (2005). Esta família ocorre em vários ambientes, sendo comum na serrapilheira, vegetação arbustiva e inclusive dentro das habitações humanas.

Como evidência de preferências por hábitat, coletou-se Amurobidae, Zoridae e Ctenidae exclusivamente no interior da mata; Oxyopidae e Miturgidae somente na área de pastagem, embora tenham sido encontrados poucos exemplares destas famílias (Tabela 1).

No mês de dezembro, obteve-se maior número de aranhas coletadas (Figura 1). Este período corresponde ao final da primavera e início do verão, cujas condições físicas ambientais propicia estado favorável a reprodução de muitas espécies de animais. Esta situação pode corroborar a explicação de maior presença de indivíduos jovens nas armadilhas, capturadas ao acaso em seu processo de dispersão.

Utilizando o índice de Diversidade de Shannon na análise comparativa para os 2 ambientes, obtevese o valor de: Mata H' 2,04143; Área de Pastagem H' 1,25427, porém pelo Teste T, não foi possível observar diferença significativa entre os ambientes, no nível de 5\% de significância. 
Tabela 1. Aranhas coletadas com pitfall no Parque Estadual Mata dos Godoy, e área adjacente, Londrina, PR, de junho de 1999 a maio de 2000, separados em : M - exemplares machos; F - fêmeas; Jov. - Jovens.

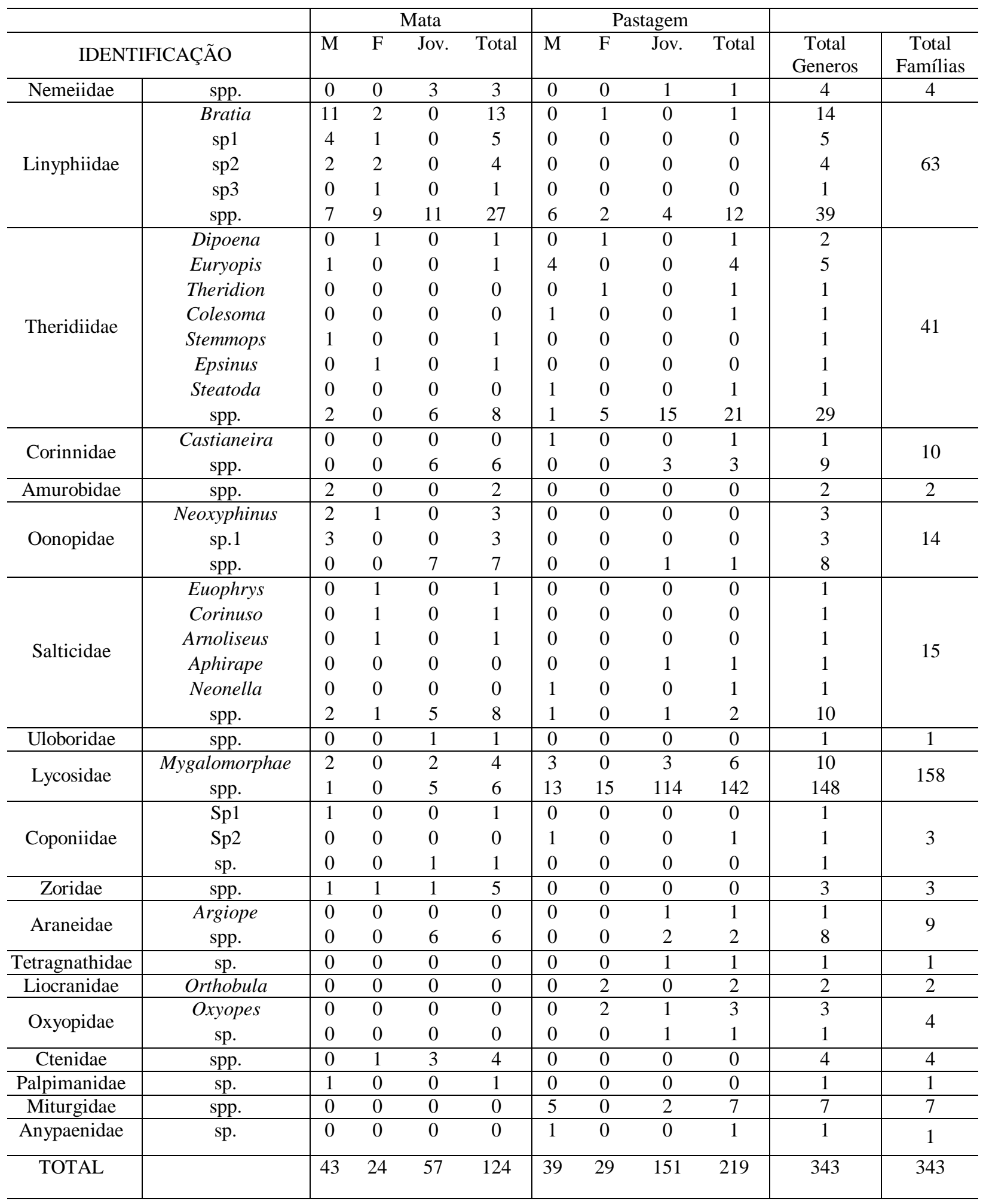




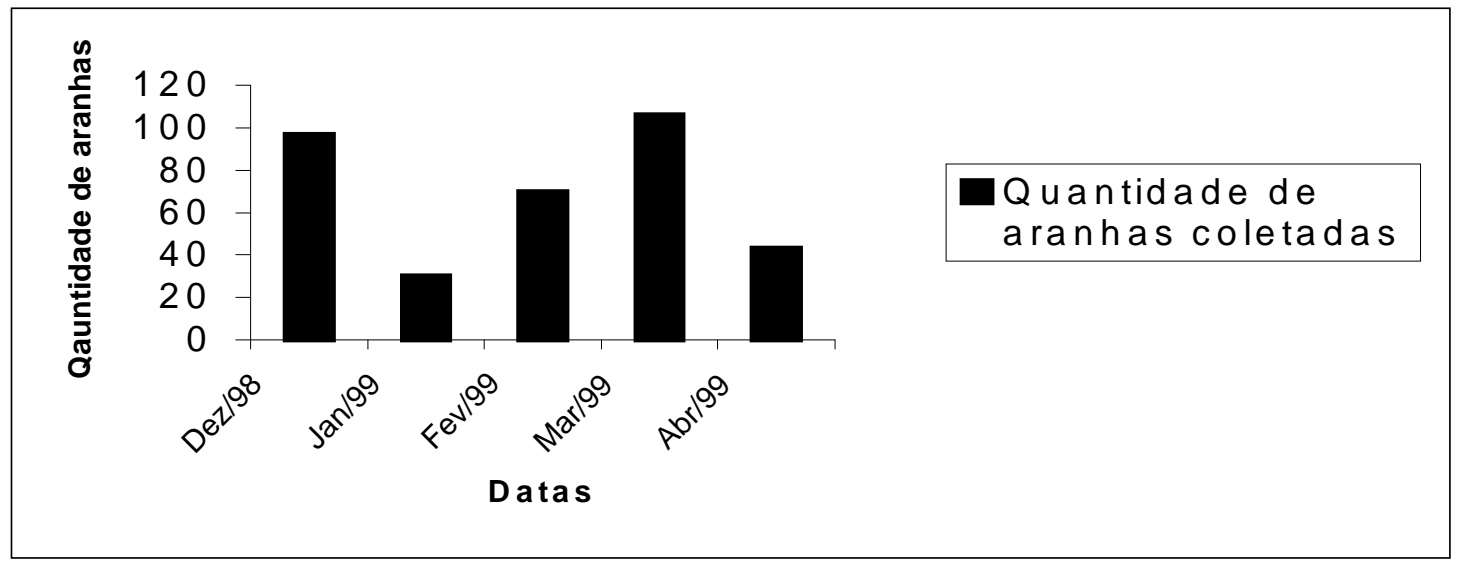

Figura 1. Quantidade de aranhas capturadas com armadilhas pitfall no Parque Estadual Mata dos Godoy, Londrina, PR, no período de dezembro de 1998 a abril de 1999

\section{Considerações Finais}

As famílias mais numerosas foram Lycosidae, Theridiidae e Linyphidae, e as duas primeiras apresentaram uma plasticidade genética que propicia viver em em ambientes com maior influência antrópica. O mesmo não ocorre com a família Linyphiidae, que tem preferência por ambientes mais preservados. Estes resultados foram semelhantes a estudos anteriores consultados na literatura. A diversidade da araneofauna no Parque Estadual Mata dos Godoy e área de pastagem não apresenta diferenças notáveis entre os ecótopos nestas análises, sendo necessários mais estudos de levantamento faunístico.

\section{Agradecimento}

Ao Dr. Antônio Brescovit do Instituto Butantana Universidade de São Paulo - USP e ao prof. Dr. Arno Antônio Lise da Pontifícia Universidade Católica, pela identificação de parte das aranhas citadas neste trabalho.

\section{Referências}

ANDRADE, R. M. G.; GALATI, E. A. B.; TAMBOURGI, V. Presence of Loxosceles similis Moenkhaus, 1898 (Araneae, Sicariidae) in Bodoquena Range, State of Mato Grosso do Sul, Brazil. Revista Brasileira de Medicina Tropical, Uberaba, v.34, n.3, p.275-277, 2001.
BENATI, K. R.; SOUZA-ALVES, J.P.; SILVA,E. A.; PERES, M. C. L.; COUTINHO, E. O. Aspectos comparativos das comuniddes de aranhas (Araneae) em dois remanescentes de Mata Atlântica do Estado da Bahia, Brasil. Biota Neotropica, Campinas,v.5, n.1a, p.[1-9], fev. 2005. Disponível em: <http://www.biotaneotropica.org.br/ v5n1a/pt/>. Acesso em: 13 abr. 2007.

BORGES, S. H; BRESCOVIT, A. D. Inventário preliminar da araenofauna (Araneae) de duas localidades na Amazõnia Ocidental. Boletim do Museu Paraense Emilio Goeldi: Zoologia, Belém, v.12, n.1, p.9-21, 1996.

BRESCOVIT, A. D.; BONALDO, A. B.; RHEIMS, C. A. A new species of Drymusa Simon, 1891 (Araneae, Drymusidae) from Brazil. Zootaxa, Auckland, New Zeland, v.697, p.1-5, 2004.

CANDIANI, D. F.; INDICATTI, R. P.; BRESCOVIT, A. D. Composição e diversidade de araneofauna (Arachnida, Araneae) de serrapilheira em três florestas urbanas da cidade de São Paulo, São Paulo, Brasil. Biota Neotrópica, Campinas, v.5, n.1, 2005. Disponível em: <http:// www.biotaneotropica.org.br/v5n1a/pt/>. Acesso em: 13 abr. 2007.

CODDINGTON, J. A.; LEVI, H. W. Systematics and evolution of spider (Araneae). Annual Review of Ecology of Systematic, Palo Alto, v.22, p.565-592, 1991.

FLÓREZ, E. Estructura y composición de una comunidad de aranãs (Araneae) em um bosque muy seco tropical de Colômbia. Boletin Entomologia Venezolana, Maracay, Venezuela, v.14, n.1, p.37-51, 1999.

HOFER, H. The Spider Community (Araneae) of a Central Amazoniam black water imundation forest (igapó). Acta Zoológica Fennica, Helsinki, v.190, p.173-179, 1998. 
INDICATTI, R. P.; CANDIANI, D. F.; BRESCOVIT, A. D.; JAPYASSÚ, H. F. Diversidade de aranhas (Arachnida, Araneae) de solo na bacia do reservatório do Guarapiranga, São Paulo, Brasil. Biota Neotropica, Campinas, v.5, n.1a, p.151-162, 2005.

MAGURRAN, A. E. Ecological Diversity and Its Measurement. Princeton: Princeton University Press, 1988.

METZGER, J. P. Estratégias de conservação baseadas em múltiplas espécies guarda-chuva: uma análise crítica. Ecossistemas Brasileiros: Manejo e conservação. 1. ed. Fortaleza: Expressão, 2003.

OLIVEIRA-ALVES, A.; PERES, M. C. L.; DIAS, M. A.; CAZAIS-FERREIRA, G. S.; SOUTO, L. R. A. Estudos das comunidades de aranhas (Arachnida: Araneae) em ambiente de Mata Attântica no Parque Metropolitano de Pituaçu-PMP, Salvador, Bahia. Biota Neotropical, v.5, n.1a, p.91-98, 2005.

PLATNICK, N. I. The World Spider Catalog, version 5.0 (online). Disponível em: <http:/research.amnh.org/ entomoly/spiders/catalog81-87/COUNTS.htm>. Acesso em: 16 ago. 2006.
RODRIGUES, E. N. Araneofauna de serapilheira de duas áreas de uma mata de restinga no município de Capão do Leão, Rio Grande do Sul, Brasil. Biotemas, Florianópolis, v.18, n.1, p.73-92, 2005.

SIMÓ, M.;PÉREZ-MILES, F.; PONCE DE LEÓN, A. F.E.; MENEGHEL, M. Relevamiento de Fauna de la quebrada de los cuervos; area natural protegida. Boletin de la Sociedad Zoologica del Uruguay, Montevideo, v.2, p.120, 1994.

TOTI, D. S.; COYLE, F. A.; MILLER, J. A. A structured inventory of appalachin grass bald and heath bald spider assemblages and a test of species richness estimator performance. Journal of Arachnology, Lubbock, v.28, p.329-345, 2000. 